\title{
Ketotifen Fumarate
}

National Cancer Institute

\section{Source}

National Cancer Institute. Ketotifen Fumarate. NCI Thesaurus. Code C47579.

The fumarate salt of ketotifen, a cycloheptathiophene derivative with anti-allergic activity. Ketotifen selectively blocks histamine $(\mathrm{H} 1)$ receptors and prevents the typical symptoms caused by histamine release. This agent also interferes with the release of inflammatory mediators from mast cells involved in hypersensitivity reactions, thereby decreasing chemotaxis and activation of eosinophils. 